\title{
TECHNOLOGY IN PRACTICE: AIRPORT SCANNING PRIVACY ISSUES
}

\author{
Daphyne Saunders Thomas, James Madison University \\ Hugh Hobson, University of the District of Columbia \\ Joan C. Hubbard, University of North Texas \\ Karen A. Forcht, ElonUniversity, kforcht@elon.edu
}

\begin{abstract}
After the September 11, 2001, terrorist attacks on the United States, the National Commission on Terrorist Attacks Upon the United States recommended that The TSA and the Congress give priority attention to improving the ability of screening checkpoints to detect explosives on passengers. As the legality of the TSA's full-body scanner program continues to be debated, the federal government is investigating the next generation of airport screening technology. The privacy debate centers on the Department of Homeland Security's use of full-body scanners to screen passengers at the nation's major airports.
\end{abstract}

Keywords: security, privacy, screening, transportation, Constitution, Congress, TSA, Homeland Security, scanners, GAO

\section{INTRODUCTION}

America's Fourth Amendment rights are being called into question as the federal government balances its obligation to guard the nation from terrorist attacks and the public's constitutional right to privacy. The privacy debate centers on the Department of Homeland Security's use of full-body scanners to screen passengers at the nation's major airports. The U.S. Constitution states that the "rights of the people to be secure in their persons, houses, papers, and effects, against unreasonable searches and seizures, shall not be violated, and no Warrants shall issue, but upon probable cause." But thus far the courts have ruled that passenger airport screening is a reasonable cost that Americans must pay to prevent death, injury and property damage from terrorist attacks.

\section{Need for Airport Security Screening}

"The amount of danger posed to the public by a person who seeks to blow up an airplane, coupled with the concept of airport boarding gates as analogous to our nation's borders, has created a situation in the United States where courts may view passenger airport screening searches as virtually per se reasonable." (Kornblatt, 2007, p. 396.

Since 2007, the Transportation Security Administration (TSA) has been deploying full-body imaging scanners in the U.S. airports. About 700 scanners have been deployed in nearly 190 airports nationwide. While the agency keeps installing these devices - which most people agree intrude on our privacy - there are real doubts whether they are actually making anybody safer. Yet, because TSA failed to solicit public comments about the scanners-in violation of federal law-the agency is "flying blind".

In 2010, the Electronic Privacy Information Center sued the Department of Homeland Security, TSA's parent department, to compel TSA to solicit public and expert input. In July, 2011, the D. C. Circuit Court of Appeals ordered TSA to "promptly" begin a rulemaking to allow for legally required public comments.

More than a year later, TSA had not even begun the process. The law empowers courts to compel agency action when it is "unreasonable delayed." TSA responded by saying that it does not have the resources to begin this public comment process. 


\section{Issues in Information Systems \\ Volume 14, Issue 1, pp.47-53, 2013}

Francine J. Kerner, chief counsel of the DHS' Transportation Security Administration insists that airport security screening "requires no warrant and no suspicion of wrongdoing," if it serves a compelling public interest. "As long as the search serves a special public need beyond law enforcement and is conducted in a reasonable fashion, it will be found to be permissible under the Fourth Amendment." Kerner argued that the department's use of full-body scanners, also known as advanced imaging technology (AIT), is in the public interest because it could prevent acts of terrorism that would jeopardize human lives and cause million of dollars in property damages. (Kerner, 2010, p. 7 of letter, exhibition in EPIC v Napolitano.)

After the September 11 terrorist attacks on the U.S., the National Commission on Terrorist Attacks Upon the United States recommended that The TSA and the Congress give priority attention to improving the ability of screening checkpoints to detect explosives on passengers. The government initially reacted to the terrorist attacks by requiring additional screening of carry-on baggage and mandating that passengers be scanned by walk-through magnetometers.

By 2004, the TSA estimated that roughly 15 percent of domestic airline passengers were also subject to secondary pat-down searches. The additional scrutiny was required if an individual triggered a magnetometer or was identified by a computer screening system. Security screeners could also require further inspection if they decided that a passenger's clothing or shoes were suspicious, or if the passenger raised a red flag by, for example, buying a one-way plane ticker or appearing on a government watch list.

"Since 2001, the TSA has implemented stricter and more extensive secondary search procedures at airport checkpoints, including modifications to the pat-down search protocols. Present day pat-down search procedures are often described as overly invasive and draw significant complaints from the traveling public. While the searches are conducted on a same-sex basis, pat-downs require contact with sensitive parts of the body, including the chest and thighs. Furthermore, screening officers conducting the search may under certain circumstances, expand the scope to even more intimate and sensitive parts of the body, such as under and in-between a woman's breasts. (Mock, 2009, p. 4.)

\section{Updated Security Techniques}

The government shifted its attention to whole-body scanners after a Christmas Day 2009 terrorism incident in which a Nigerian man flying into Detroit allegedly tried to detonate an explosive device hidden in his underwear. In the aftermath, President Obama vowed to strengthen airport security and screening measures. In the never-ending race to protect our country, we have to stay one step ahead of a nimble adversary. That's what these steps are designed to do, Obama said.

Homeland Security Secretary Janet Napolitano in July, 2010 announced plans to expand use of whole-body AIT scanners at U.S. airports. Those scanners use low-level x-rays to create anatomically detailed pictures of each passenger's body. DHS officials say the machines can detect weapons and explosives that individuals might try to conceal under layers of clothing and sneak on board airplanes. According to the Transportation Security Administration, the advanced-technology body scanners will eventually be used as the "primary screening" method at airport checkpoints. As of March 2011, the federal government had deployed 500 imaging technology units at U.S. airports, and set a goal of deploying nearly 1,300 AIT machines by the end of 2012. (Kane; Kair, March 2011, p. 2--this is a new document.)

TSA officials insist that the government will protect the privacy of passengers inspected with the whole-body scanners by blurring each person's appearance and by permanently deleting the images once they are stored. To further enhance privacy, regulators say that the staff viewing the images are being stationed in remote locations and will not come into contact with the passengers being screened. In testimony before Congress, government regulators said that "AIT machines do not produce photographic 


\section{Issues in Information Systems \\ Volume 14, Issue 1, pp.47-53, 2013}

quality images that would permit recognition of the person screened. A facial blur has also been applied to both the millimeter wave and backscatter technologies." The agency's screening protocols "ensure that such screening does not unreasonably intrude on a passenger's privacy in the airport environment and that the public's privacy concerns related to AIT screening are adequately addressed." DHS regulators also note that the scans are optional and passengers may request an alternative method of inspection, which would include a physical pat-down. TSA officials say that "more than 98 percent of individuals selected for AIT screening have opted to be screened by this technology over other screening methods such as a pat down." (Kane; Kair, 2011, p. 3, 4.)

\section{Concerns About Individual Privacy}

The government's assurances continue to be questioned by privacy, consumer rights, and civil rights organizations that contend that the full-body scanners produce detailed images that are the equivalent to a "digital strip-search." Marc Rotenberg, executive director of Electronic Privacy Information Center, argues that "[w]ithout a warrant, the government doesn't have a right to peer beneath your clothes without probable cause." (Rotenberg, 2010, p. 5.)

According to passenger complaints filed with TSA and obtained by EPIC, airport personnel have been negligent about explaining alternative screening procedures and in some cases have mandated that passengers undergo whole-body screening. In its petition to DHS, the privacy group argued that "as a matter of pattern, practice and policy, the TSA does not offer air travelers a meaningful alternative to [fullbody scanner] searches in airports equipped with FBS devices."

Legal experts disagree on the government's authority to use full-body scanners. The courts tend to give great deference to the government's concerns about national security, noted Jeffrey Rosen, law professor at George Washington University and author of "The Naked Crowd: Reclaiming Security and Freedom in an Anxious Age." "But in this case, there's strong argument that the TSA's measures violate the Fourth Amendment," according to Rosen, "'non-routine' searches, such as strip-searches or body-cavity searches, require some individualized suspicion -- that is, some cause to suspect a particular traveler of wrongdoing. Neither virtual strip-searches nor intrusive pat-downs should be considered 'routine,' and therefore courts should rule that neither can be used for primary screening...They reveal a great deal of innocent but embarrassing information and are remarkably ineffective at revealing low-density contraband." (Rosen in the Washington Post, 2010, p. 6 of printout)

Fred H. Cate, a law professor at Indiana University's Center for Applied Cybersecurity Research, states that the scanners detect so many false reports of anomalies that "the AITs are not merely failing in practice to protect the air transport infrastructure against threats, but are actually interfering with TSA agents' ability to do so by sending them on so many wild good chases." (Cate, March 2011, p.9--new report)

\section{Special Nature of Personal Issues}

The personal trauma of facing the TSA's airport screening process was related to Congress in March 2011 in testimony by Alaska State Rep. Sharon Cissna, who had had a mastectomy due to breast cancer. Cissna was stopped at an airport when she refused to undergo a full-body scan, which would have disclosed her physical anomaly. "The TSA agent began to tell me what would soon happen regarding where she was going to touch me and the force-forgotten memory of the previous intensive physical search returned," Cissna said. When Cissna refused the additional screening, she was surrounded by police, TSA officials and airport employees, which she said could have been "very intimidating because of their positions of authority and the difference in height between me and those surrounding me."

Cissna provided a passionate critique of the government's security system. "For nearly fifty years I've fought for the rights of abuse survivors and it is this population that is the most harmed by unwanted 


\section{Issues in Information Systems \\ Volume 14, Issue 1, pp.47-53, 2013}

physical touch. My wonderful state of Alaska depends on air flight as a mandatory means of transportation, both intra and interstate of our vast land. We also sadly rank first in the nation for both men and women who have been abused. Logic suggests that the recent introduction of the full body scan (itself a potentially harmful source of radiation) is the very last thing a molested person could deal with because it would result in yet more trauma from the groping of strangers. Most tragic of these policies are the silent masses that are traumatized and dishonored at the hands of their own government in the name of 'safety' policies." (Cissna, March 201).

\section{Religious Freedom Concerns}

The public interest groups argue that the airport scanners also violate the Religious Freedom Restoration Act, which bars the government from placing a substantial burden on a person's exercise of religion unless the government demonstrates a compelling interest. The groups' petition contends that the scanners violation the religious tenets of Muslims and other spiritual groups by allow the government to capture photos of passenger's naked bodies. The scanners have been banned in some Muslim countries.

In addition, critics say that the airport scanners report a high level of false "anomalies" in the passengers' images. "The AITs are not merely failing in practice to protect the air transport infrastructure against threats, but are actually interfering with TSA agents' ability to do so by sending them on so many wild good chases," according to Fred H. Cate, a law professor at Indiana University's Center for Applied Cybersecurity Research. (Cate, March 2011, p.9)

The U.S. Government Accountability Office also raised questions about the value of the scanning technology. In an October 2009 report, the government agency said that the TSA was deploying the body scanning machines without fully assessing whether they could detect "threat items" concealed on the body. In a March 2010 follow-up report, GAO said it "remains unclear" whether the advanced scanners would have detected the explosives that police allege the Nigerian passenger tried to detonate on a jet bound for Detroit in 2009.

\section{Health Concerns with Radiation}

There are two kinds of scanning devices—back-scatter and millimeter wave. Back-scatter scanning machines send narrow, low-density X-ray beams over the subject, front and back, at high speeds, which just barely penetrate the clothing. The X-ray radiation reflects off the body - and of any objects hidden on that person. The process takes between 6 to 8 seconds.

Millimeter-wave machines are typically composed of twin vertical arrays of extremely highfrequency transmitters that circle the passenger and create a three-dimensional image. The transmitters emit beams of radio frequency energy, which bounces off sub-clothing surfaces and exposes hidden items. Like back-scanner machines, the mms scan requires several seconds before an image is produced.

Some medical experts warn that the whole-body scanners could present safety concerns for passengers that undergo screening and for airport personnel who work near the scanners. In an April letter to White House science advisor John Holdren, four University of California scientists warned that radiation from the scanners has been underestimated and could cause health impacts in children, older travelers, pregnant women, and individuals with a greater susceptibility to cancer. Calling for a thorough review of the potential health impacts, the scientists concluded that "it appears that real independent safety data do not exist."

David J. Brenner, director of the Columbia University Center for Radiological Research, agreed that the scanners have the potential of increasing the incidence of cancer. "In that x-ray backscatter scans have become a primary screening measure, very large numbers of people will likely be exposed to very 


\section{Issues in Information Systems \\ Volume 14, Issue 1, pp.47-53, 2013}

small radiation-associated cancer risks from the associated radiation exposure. Given the very large numbers of scans involved, potentially up to one billion each year in the U.S., there is a significant likelihood that, amongst the scanned population, there will be some cancers produced by the associated radiation exposure. A best estimate is around 100 cancers per year, though this number is quite uncertain." (Brenner, March 2011, p. 2)

However, Homeland Security officials say that the x-ray imaging technology is safe and estimated that the radiation dosage individuals receives from the advanced-imaging machines is less than the level that passengers get while flying on an airplane or from naturally occurring background radiation levels.

\section{How the Scanners Actually Work}

Scanning technologies are now in use at all major airports in the U.S. According to the TSA, the scanners only see what is required to keep weapons and explosives off airplanes. The back-scatter device and the MMS machines each produce different kinds of images. While the former creates an almost cartoonish two-dimensional snapshot of the inspection subject, the latter produces a holographic 3D image.

The TSA has given numerous assurances that every machine used in airports will feature face-andgenitalia-obscuring checks. The so-called "modesty algorithm" are incapable of data storage and that once an inspection ends and the image is cleared, it disappears forever.

\section{Legal Challenges of Airport Scanning}

The government's plan to use whole-body scanners has been the subject of a series of legal challenges. In April 2010, the Electronic Privacy Information Center and 33 other public interest groups petitioned the TSA to suspend the scan program, arguing that the screening is unconstitutional because it subjects passengers to an unreasonable search and amount to an unlawful invasion of privacy. Similar concerns have been raised in other countries. In Britain, for example, airport security personnel are prohibited from scanning children due to warnings that the machines may violate national child pornography laws. The European Commission is also warning that body scanners raise fundamental privacy concerns and recommending less intrusive measures.

In July 2010, EPIC also filed a lawsuit challenging the TSA's decision to make body scanners the primary screening technique in U.S. airports, and asking the court to suspend the body- scanner program, pending independent review. That suit charges that "the TSA has acted outside of its regulatory authority and with profound disregard for the statutory and constitutional rights of air travelers." Joining EPIC in the suit are three frequent air travelers: the Council on American-Islamic Relations' legal counsel Nadhira AlKhalili, human rights activist Chip Pitts and security expert Bruce Schneier. The petitioners claim that the government program violates the Administrative Procedure Act, the Privacy Act, the Video Voyeurism Prevention Act, the Religious Freedom Restoration Act and the Fourth Amendment. (EPIC v. the Department of Homeland Security, Case No. 10-1157)

TSA officials responded that "Given the nature of the AIT program, petitioners face no likelihood of irreparable harm. The program is designed to respect individual sensibilities regarding privacy, modesty and personal autonomy to the maximum extent possible, while still performing its crucial function of protecting all members of the public from potentially catastrophic events. The optout provision and the operating protocols requiring immediate deletion of images and preventing their misuse highlight the AIT program's sensitivity to potential concerns on the part of passengers ... Petitioners have not shown that agency implementation of a system with these privacy-respecting 


\section{Issues in Information Systems \\ Volume 14, Issue 1, pp.47-53, 2013}

and privacy-protecting features creates a significant risk of irreparable harm to members of the flying public, and their anecdotal assertions furnish no basis for .shutting down this essential transportation security program."

EPIC has filed a series of Freedom of Information Act requests and lawsuits seeking data on the scanners' ability to store and transmit scanned body images that the machines take. The federal agencies had insisted that the images would be discarded as soon as they were viewed by TSA experts. But the TSA's technical specifications require that scanners be able to store and transmit images. Government officials say those functions are shut off when the devices are installed at airports. Nonetheless, the Justice Department's U.S. Marshals Service has conceded that it saved 35,000 images taken with similar machines at a Florida federal courthouse. The Homeland Security Department has also admitted to saving over 2,000 photos from airport body scanners taken during training.

Congress has begun weighing in on the debate over full-body scanners. In 2010, Senators Bob Bennett, R-Utah, and Amy Klobuchar, D-Minn., introduced legislation supporting the DHS plans to install full-body scanners. The lawmakers' bill would require all commercial airports in the United States to deploy body imaging scanners by 2013 .

But as evidence emerged that government had saved body image scans, six Senators sent a letter to the U.S. Marshal Service asking for a full explanation of the privacy practices. In addition, Senators Susan Collins, R-Maine; Richard Burr, R-N.C.; and Tom Coburn, R-Okla., wrote to DHS secretary Janet Napolitano objecting to the government's plans to expand the airport body scanner program in light of potential health concerns. The lawmakers asked "why the Department continues to purchase this technology when legitimate concerns about its safety appear to remain unanswered." The Senators were particularly concerned that airport personnel could receive multiple doses of radiation every work day. They urged the agency to work with independent experts to study the technology's health effects on travelers and airport personnel.

In March 2011, the House held hearings questioning the TSA's whole-body scanning program. In February, New Mexico Sen. Tom Udall introduced legislation requiring the federal government to install the advanced automatic target recognition software in all scanning machines by 2012 . Udall said the current technology produces images that are "highly revealing and many passengers are uncomfortable eing screened by the technology. Unfortunately, TSA's policy for passengers who refuse AIT screening is to conduct a full apt-down -- hardly an ideal alternative for someone with privacy concerns." (Udall, February 2011, p. 1--new document).

EPIC officials say that hundreds of airport passengers have filed complaints about the DHS' increased screening. But according to November 2010 Washington Post-ABC News public opinion poll, nearly two-thirds of Americans support the new full-body security-screening machines at the country's airports. Half of those polled, however, opposed the enhanced pat-down searches that are imposed on passengers who refuse to be scanned. According to the TSA, less than 3 percent of travelers receive the patdowns. "About a third of all Americans see the new scanning machines as a potential health risk, but most say that's not a big concern." Despite those concerns, the poll found that more than 70 percent of those polled said the scanning program would not influence their travel plans. (Jon Cohen; Ashley Halsey III, Washington Post, November 2010, p. 1--new document)

The November 2010 public opinion polls showed that travelers had slightly tempered their enthusiasm for whole body scanners since the weeks following the Christmas day 2009 airplane incident. At that time, Gallup and CNN/Opinion Research Corporation released separate polls showing that almost 80 percent of the public backs the government screening program.

In the Gallup poll, 67 percent of those surveyed said they would not personally be "too uncomfortable" in undergoing such a scan, with close to half (48\%) saying they would not be 


\section{Issues in Information Systems \\ Volume 14, Issue 1, pp.47-53, 2013}

uncomfortable at all. The travelers polled by Gallup also said they would prefer to undergo a whole body scan rather than a physical pat-down from airport security personnel. Scans were favored over pat-downs by a 70 to 22 margin. The CNN/Opinion Research Corporation poll indicated that 72 percent of the public would not be concerned about undergoing a full-body scanner, with 27 percent saying they would be uneasy. Given the choice between a full-body scanner or a physical pat-down, 82 percent of those surveyed would rather undergo a full body scan. The CNN survey also showed that 76 percent of the public did not believe that the scanners pose a health risk to people who go through them.

\section{CONCLUSIONS}

As the legality of the TSA's full-body scanner program continues to be debated, the federal government is investigating the next generation of airport screening technology. The companies that make the existing scanners are developing software designed to block the view of passenger body parts in favor of cartoon-like, gender-neutral images. TSA is beginning to field test that equipment, known as automatic target recognition, at some domestic airports. Regulators say that the software "enhances passenger privacy by eliminating passenger-specific images and instead highlighting the areas with a detected anomaly on a generic outline of a person. Pat-downs used to resolve such anomalies will be limited to the areas of the body displaying an alarm unless the number of anomalies detected requires a full-body pat down." (Kane; Kair, 2011.

\section{REFERENCES}

Abeyratne, Ruwantissa, March 2010, "Full Body Scanners at Airports--the Balance Between Privacy and State Responsibility," Journal of Transportation Security," Volume 3, Number 2, 73-85.

Harris, David A., 1996, "Superman's X-ray Vision and the Fourth Amendment: The New Gun Detection Technology," Temple University Law Review, 1-60.

Klitou, Demetrius, 2008, "Regulatory Issues in Body Scanners, Backscatter Body Scanners - A Strip Search by Other Means," Computer Law \& Security Report, Volume 24, Issue 4, 316-325.

Kornblatt, Sara, 2007, "Are Emerging Technologies in Airport Passenger Screening Reasonable under the Fourth Amendment," Loyola of Los Angeles Law Review, 385-412.

Lew, Jessica D., 2005, "Secondary Screening Procedures for Airports: Putdowns for Pat-downs," Laworld, http://www.makdap.com.au/docs/LAWorld\%20Vol\%2019.pdf.

Mackey, David A., June 2007, "The 'X-Rated X-Ray': Reconciling Fairness, Privacy, and Security," Criminal Justice Studies, Volume 20, Issue 2, 149-159.

Minert, Steven R., 2006, "Square Pegs, Round Hole: The Fourth Amendment and Preflight Searches of Airline Passengers in a Post-9/11 World," Brigham Young University Law Review, 1631-1667.

Mock, Tobias W., 2009, "The TSA's New X-ray Vision: The Fourth Amendment Implications of 'BodyScan' Searches at Domestic Airport Security Checkpoints," Santa Clara Law Review, 213-252.

Solomon, Julie, 2008, "Does the TSA Have Stage Fright? Then Why Are They Picturing You Naked?" Journal of Air Law and Commerce, 73 J. Air L. \& Com. 643-671.

Viña, Stephen R., 2001-2002, "Virtual Strip Searches at Airport: Are Border Searches Seeing Through the Fourth Amendment?" Texas Wesleyan Law Review," 417-43. 